\title{
Cemented Hip Designs are a Reasonable Option in Young Patients
}

\author{
Vincent Busch MD, Rik Klarenbeek MD, \\ Tom Slooff MD, PhD, B. Willem Schreurs MD, PhD, \\ Jean Gardeniers MD, PhD
}

Published online: 20 April 2010

(C) The Author(s) 2010. This article is published with open access at Springerlink.com

\begin{abstract}
Background Young patients with degenerative cartilage disease of the hip remain a challenge for the orthopaedic surgeon. Different treatment options are available of which uncemented hips are the most popular owing to long-term concerns about cemented implants. As an alternative, we have used a cemented hip design in combination with bone impaction grafting in patients with acetabular defects.

Questions/purposes We therefore determined the survival rates and radiological failures of cemented THA in patients younger than 30 years and reported clinical scores, complications and current state of the revised THAs.

Methods We retrospectively reviewed all 48 patients (69 hips) younger than 30 years at the time of surgery who had a primary cemented THA performed between 1988 and 2004. Acetabular defects were reconstructed using bone impaction grafting in 29 hips. Mean age at surgery was 24.6 years (range, 16-29 years). Revisions were documented, radiographs were analyzed, and the Kaplan-Meier method was used to determine survival for different end
\end{abstract}

One or more of the authors (BWS, JWMG) have received funding from Stryker-Howmedica, Newbury, UK. All received financial support was directed solely to a research fund and no personal benefits were received.

Each author certifies that his or her institution approved the human protocol for this investigation, that all investigations were conducted in conformity with ethical principles of research.

V. Busch, R. Klarenbeek, T. Slooff, B. W. Schreurs,

J. Gardeniers $(\square)$

Department of Orthopaedics 357, Radboud University Nijmegen

Medical Centre, PO Box 9101, 6500 HB Nijmegen,

The Netherlands

e-mail: J.Gardeniers@ orthop.umcn.nl points. No patient was lost to followup, three patients (four hips) had died. Minimum followup was 2 years (mean, 8.4 years; range, $2-18$ years).

Results Eight hips were revised (three for infection and five for aseptic loosening) and one hip dislocated for which open reduction was necessary. One additional cup was considered a radiographic failure. The 10 -year survival was $83 \%$ (95\% confidence interval, $69 \%-92 \%$ ) with revision for any reason as the end point and $90 \%$ (95\% confidence interval, 77\%-96\%) with revision for aseptic loosening. Conclusions We found a high survival rate of these cemented THA in young patients. In young patients with acetabular bone defects we recommend reconstruction using cemented implants with bone impaction grafting. Level of Evidence Level IV, therapeutic study. See Guidelines for Authors for a complete description of levels of evidence.

\section{Introduction}

THA restores hip function, relieves pain, is cost-effective, and associated with high survival rates [10, 24]. Given this experience indications for THA have now been extended to younger ages including patients younger than 30 years [2$4,9,12,16,17,19,20,23,28-30,32]$. However, most patients under the age of 30 years with osteoarthritis have some underlying disorder, such as developmental dysplasia of the hip, Legg-Calvé-Perthes disease, or juvenile rheumatoid arthritis. Bone stock deficiencies and bone deformations often are present and can be an additional problem in achieving a stable and durable reconstruction.

Several options are available to deal with acetabular defects in young patients. The most commonly used is likely an uncemented cup and if necessary a reinforcement 
ring, placed with or without bone grafts. Reported survival rates (with revision as an endpoint) on uncemented hips in patients younger than 30 years with a minimal followup of 10 years vary from $49 \%$ [31] to $90 \%$ [23]. We have preferred a cemented THA in our young patients and to reconstruct any acetabular defects with bone impaction grafting [25] in combination with a cemented cup.

The purpose of our study was to (1) determine survival of cemented prostheses in patients younger than 30 years and whether differences exist between hips placed with and without acetabular bone impaction grafting; (2) determine the clinical outcome of the surviving hips; (3) define radiographic failures; and (4) determine complications and current state of revisions.

\section{Patients and Methods}

We retrospectively reviewed all 48 patients (69 hips) younger than 30 years of age who had primary cemented THAs for primary or secondary osteoarthrosis between April 1988 and May 2004. Indications for THA were mainly osteonecrosis of the femoral head and juvenile rheumatoid arthritis (Table 1). Nineteen hips had previous surgeries at the hip. We excluded patients who had reconstruction for tumors. There were 32 female (46 hips)

Table 1. Indications for THA

\begin{tabular}{ll}
\hline Indication & $\begin{array}{l}\text { Number } \\
\text { of hips }\end{array}$ \\
\hline Juvenile rheumatoid arthritis & 18 \\
Osteonecrosis of femoral head & 21 \\
Systemic lupus erythematosus & 7 \\
Acute lymphatic leukemia & 3 \\
Crohn's disease & 3 \\
Nephropathy, kidney transplantation & 2 \\
Hypothalamic disorder & 1 \\
Aplastic anemia & 1 \\
Wegener's disease & 1 \\
Unknown origin & 3 \\
Developmental dysplasia of the hip & 7 \\
Multiple epiphyseal dysplasia & 2 \\
Legg-Calvé-Perthes disease & 6 \\
Ankylosing spondylitis & 5 \\
Morquio's disease & 2 \\
Ankylosis of unknown origin & 2 \\
Polycystic disease of the femoral head of unknown origin & 2 \\
Arthritis and osteomyelitis & 2 \\
Posttraumatic osteoarthritis & 1 \\
Psoriatic arthritis & 1 \\
\hline
\end{tabular}

and 16 male patients ( 23 hips) with a mean age at operation of 24.6 years (range, 16.0-29.0 years). Twenty-one bilateral THAs were performed, and in two of these patients, the procedure was completed in a single surgery. Three patients (four hips) died 1.4, 8.6 and 9.1 years after operation but they were evaluated at the outpatient clinic on a regular basis until their deaths and the data were included in the analyses. One patient with Crohn's disease died of sepsis after colorectal surgery and another patient died because of aplastic anemia. The cause of death of a patient with juvenile rheumatoid arthritis was not known. The minimum followup was 2 years (mean, 8.4 years; range 2-18 years). No patient was lost to followup.

A posterolateral approach was used in all hips without a trochanteric osteotomy. Acetabular defects were classified according to system of the American Academy of Orthopaedic Surgeons (AAOS) Committee on the Hip [6]. A Type I defect was seen in five hips, a Type II defect in 16 hips, and a Type III defect in eight hips. A metal mesh was used in 14 hips to reconstruct a segmental defect. The remaining cavitary defect was reconstructed with bone impaction grafting. This technique has been reported in detail [25]. Twenty-nine of the 69 hips had acetabular impaction grafting using femoral head autografts in 23 hips. Fresh-frozen, nonirradiated femoral head allografts were used in three hips with a Type III defect, using one or two femoral heads. In three hips, both autografts and an allograft femoral head were used. Second-generation cementing technique was applied in all hips. All patients received systemic prophylactic antibiotics ( $2 \mathrm{~g}$ cefazolin) immediately before surgery.

Several types of femoral and acetabular components were used (Table 2). Sizes of femoral heads used were $22 \mathrm{~mm}$ (9 hips), $28 \mathrm{~mm}$ (49 hips) and $32 \mathrm{~mm}$ (11 hips). Before 1989, Palacos ${ }^{\circledR}$ bone cement (Merck, Darmstadt, Germany) was used and Surgical Simplex ${ }^{\circledR}$ (Stryker) from 1989 on.

Postoperatively all patients had prophylactic anticoagulation therapy for 6 weeks or 3 months after surgery. Indomethacin was administered for 7 days to prevent heterotopic ossification. After 24 hours, passive movements were allowed, followed by ambulation with partial weightbearing with two crutches. After 6 weeks, full

Table 2. Types of implant

\begin{tabular}{|c|c|c|c|}
\hline Type of acetabular implant & $\begin{array}{l}\text { No. of } \\
\text { hips }\end{array}$ & $\begin{array}{l}\text { Type of femoral } \\
\text { implant }\end{array}$ & $\begin{array}{l}\text { No. of } \\
\text { hips }\end{array}$ \\
\hline Stryker Exeter ${ }^{\mathrm{TM}}$ & 29 & Stryker Exeter ${ }^{\mathrm{TM}}$ & 45 \\
\hline Depuy Elite ${ }^{\mathrm{TM}}$ Plus LPW & 26 & Depuy Elite ${ }^{\mathrm{TM}}$ & 13 \\
\hline Zimmer Müller ${ }^{\mathbb{R}} /$ Allopro ${ }^{\mathbb{R}}$ & 14 & M.E. Müller ${ }^{\circledR}$ straight & 11 \\
\hline
\end{tabular}


weightbearing was allowed. Patients with an acetabular bone graft had a slightly altered protocol, allowing touch weightbearing during the first 6 weeks and from 6 to 12 weeks partial weightbearing allowing $50 \%$ of body weight. Patients with extensive acetabular reconstructions initially had a 6-week period of bed rest.

Patients were assessed clinically and radiographically at 6 and 12 weeks, at 6 months, at 1 year, and annually or biannually thereafter. The Harris hip score (HHS) [13] and the Oxford Hip Questionnaire Score (OHQS) [7] were used for clinical evaluation. Based on preoperative radiographs and the surgical reports, acetabular defects were classified according to the system of the AAOS Committee on the Hip [6].

Three of us (VB, RK, BWS) independently reviewed serial radiographs to determine the structural quality of the bone graft, radiolucencies and osteolysis, prosthesis migration, socket tilting, and heterotopic ossification. Graft incorporation was defined as the manifestation of a regular

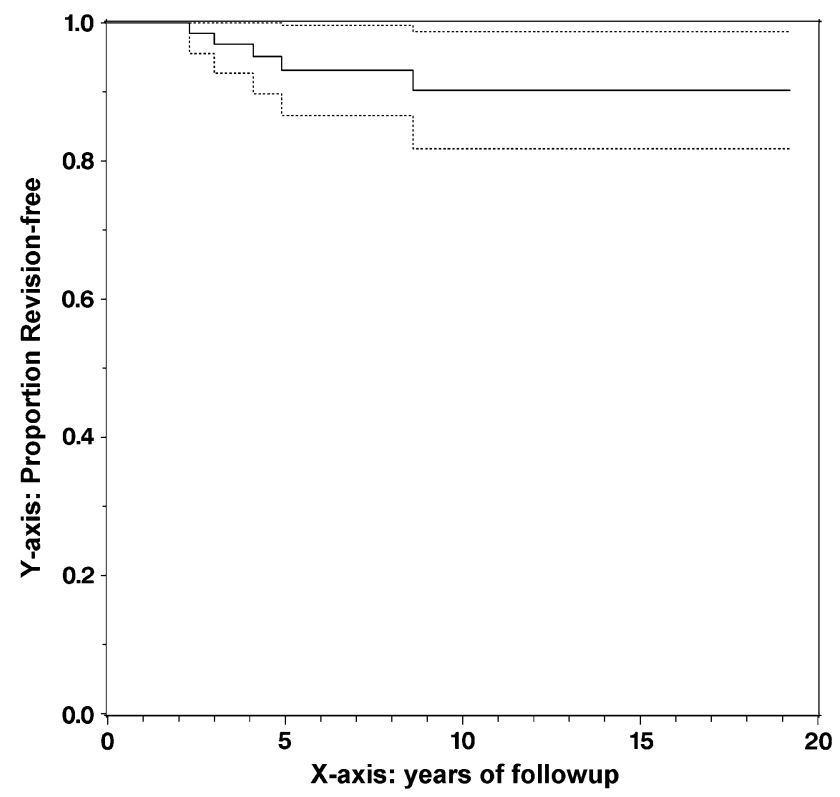

Fig. 1 A Kaplan-Meier curve shows survivorship for the total group with revision for aseptic loosening as the end point. Dotted lines indicate $95 \%$ confidence intervals. radiodensity and trabecular bone structure throughout the graft and host bone with a continuous trabecular pattern according to Conn et al. [5]. Radiolucent lines more than $2 \mathrm{~mm}$ wide were described and were defined as stable or as progressive in time. Acetabular zones were identified using the criteria of DeLee and Charnley [8] and a radiographic failure was defined as radiolucent lines in all three zones and/or migration of $5 \mathrm{~mm}$ or more in any direction on the AP-pelvic view relative to the interteardrop line. Radiolucent zones on the femoral side were evaluated using the method of Gruen et al. [11]. Loosening of the femoral component was defined using the criteria of Harris et al. [14]. Definite loosening of the stem was defined as the appearance of a radiolucent line in all Gruen zones that did not exist on the immediate postoperative radiographs, a crack in the cement or fracture of the stem. Femoral prosthetic subsidence was considered abnormal if it was more than $2 \mathrm{~mm}$ [18]. Heterotopic ossification was classified according to Brooker et al. [1].

Followup radiographs were complete for 68 of the 69 hips; for one patient (one hip), a recent radiograph was not available due to her pregnancy at the time of review.

Kaplan-Meier survivorship analysis [15] was performed for the whole group, as well as for hips with and without acetabular bone impaction grafting. End points used were revision of one or both components for any reason and revision for aseptic loosening and radiographic loosening. The log-rank test was used to compare survival of the bone impaction group and the non-bone impaction group.

\section{Results}

Survivorship of the total group was $90 \%$ (95\% CI, 77\%$96 \%$ ) at 10 years with revision for aseptic loosening as the end point (Fig. 1) (Table 3). With revision for aseptic loosening as the end point, the primary cemented cups had a survivorship of $87 \%(95 \% \mathrm{CI}, 68 \%-95 \%)$ and the bone impaction group $95 \%(95 \%$ CI, 72\%-99\%) at 10 years (Fig. 2). No differences in survival between the primary cemented and the bone impaction group were found. Eight hips had been revised. Three hips were revised because of

Table 3. Survivorship for different categories of patients

\begin{tabular}{|c|c|c|c|}
\hline \multirow[t]{2}{*}{ Category of patients } & \multicolumn{3}{|c|}{10 -year survivorship in $\%(95 \% \mathrm{CI})$} \\
\hline & $\begin{array}{l}\text { End point revision } \\
\text { for aseptic loosening }\end{array}$ & $\begin{array}{l}\text { End point revision } \\
\text { for any reason }\end{array}$ & $\begin{array}{l}\text { End point radiographic } \\
\text { failure }\end{array}$ \\
\hline Primary cemented hips & $87(68-95) \%$ & $80(59-90) \%$ & $87(67-95) \%$ \\
\hline Acetabular bone impaction grafting & $95(72-99) \%$ & $89(62-97) \%$ & $95(72-99) \%$ \\
\hline All patients & $90(77-96) \%$ & $83(69-92) \%$ & $89(77-95) \%$ \\
\hline
\end{tabular}




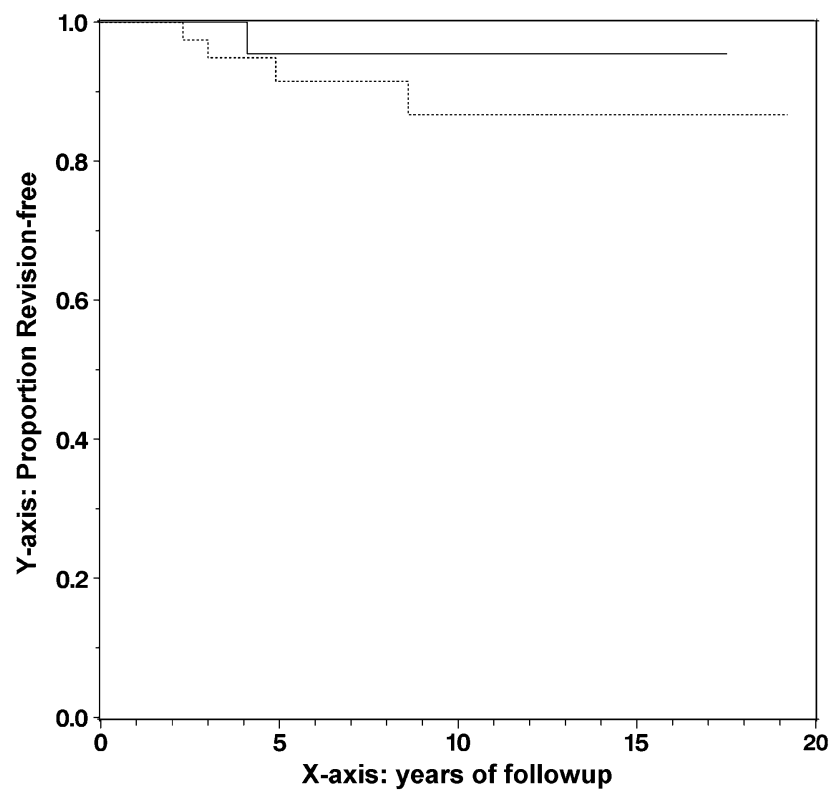

Fig. 2 A Kaplan-Meier curve shows survivorship for the bone impaction group (solid line) and the primary cemented group (dotted line) with revision for aseptic loosening as the end point.

septic loosening at 5.7, 7.3, and 7.8 years after the index operation. In five hips, only a revision of the cup was performed because of aseptic loosening after 2.3, 3.1, 4.1, 5.0 and 8.6 years. Two revised cases had impaction grafting of which one patient had primary diagnosis juvenile rheumatoid arthritis. No additional stem revisions were performed.

The mean HHS of the 57 surviving hips in 37 living patients was 89 (range, 55-100) and the mean OHQS was 19 (range, 12-42) after a minimum followup of 2 years (mean, 8.4 years; range, 2-18 years). One patient with juvenile arthritis had a HHS of 55 and an OHQS of 42 and was limited in walking distance, unable to climb stairs, and experienced moderate pain.

Progressive acetabular radiolucent lines were seen in six of the 61 surviving hips: in one zone in four hips and in two zones in two hips. Osteolysis was evident in three hips and limited to one zone in two cases; the third case involved two zones. Socket migration of more than $10 \mathrm{~mm}$ had occurred in one hip. Tilting of the acetabular component was seen in two patients, of which one was progressive the latest years of followup. Heterotopic ossification was seen in 14 of the 61 surviving hips and was classified as Grade II (11 hips) and Grade III (three hips). In THAs with bone impaction grafting, incorporation of the graft was seen in all hips (Fig. 3). None of the femoral components migrated more than $2 \mathrm{~mm}$. A radiolucent line with an osteolytic lesion was seen in one hip in Gruen Zone 7; none of the surviving femoral components had evidence of radiographic loosening. One cup was considered loose, but
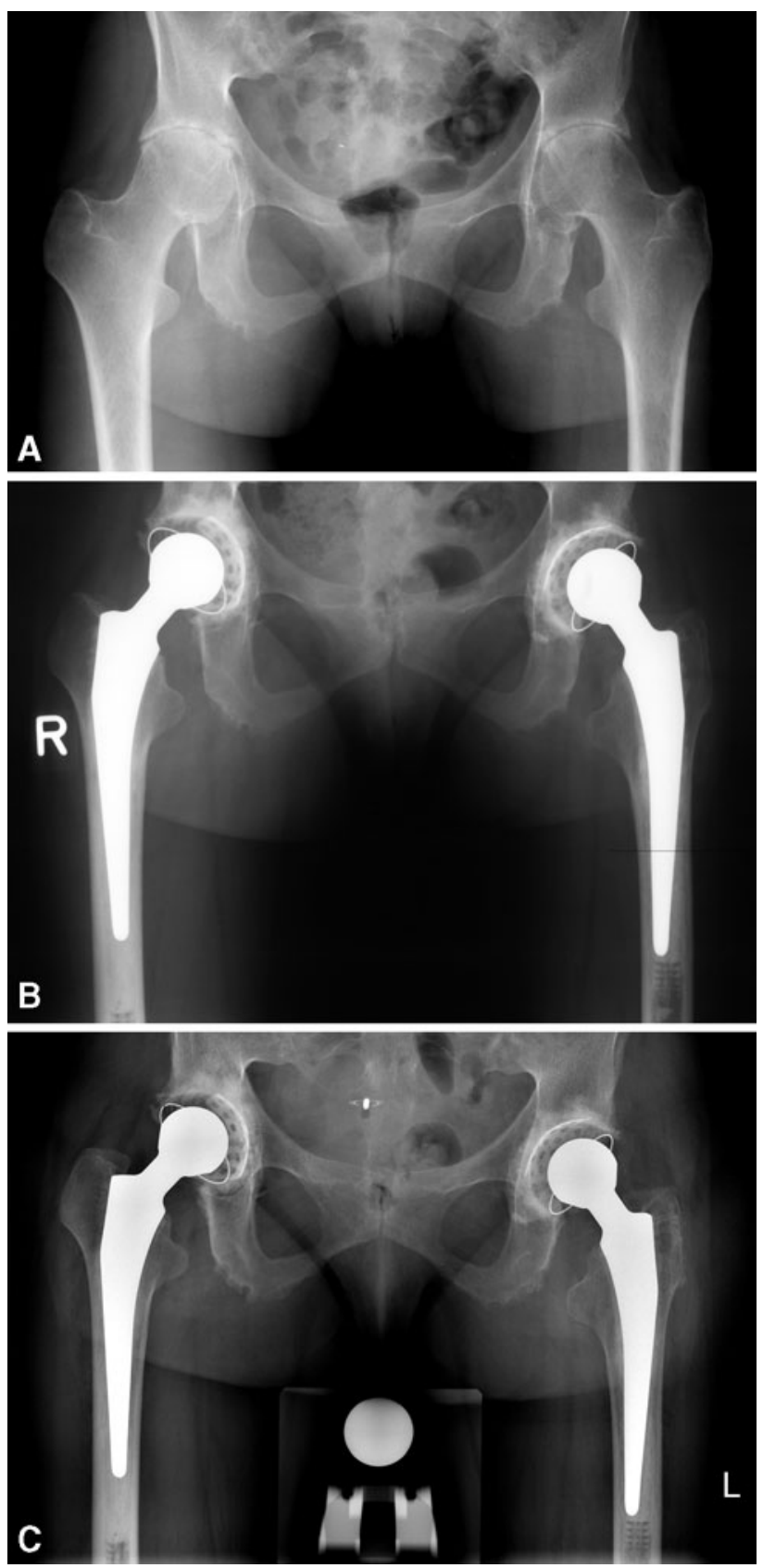

Fig. 3A-C (A) A preoperative radiograph shows the hips of a 29-year-old woman with bilateral secondary osteoarthritis due to Bechterew's disease who had the longest followup in our series. (B) A postoperative radiograph shows the hips after bilateral reconstruction of the acetabulum with bone impaction grafting for a cavitary defect and a cemented prosthesis. (C) A radiograph at 17 and 18 years after the reconstruction shows incorporation of the bone graft and no signs of loosening except for an acetabular radiolucent line at the right hip in zone III.

revision has not been performed yet because of absence of complaints.

One patient (one hip) underwent an early reoperation due to suspicion of infection but recovery was complete 
after débridement and antibiotics. Two patients had a traumatic dislocation of the prosthesis, and closed reduction was successful in one, but for the other operative repositioning was needed. In one patient exploration of the femoral nerve was performed because of neurological deficit. The proximal part of the nerve could not be detected and recovery was incomplete. All eight revisions were performed in our own institute and all patients were followed after their revision. In seven hips, acetabular reconstruction with bone impaction grafting at revision surgery was performed and a cemented cup was placed. In two of the three revisions of the stem, reconstruction of a femoral defect was necessary using femoral bone impaction grafting and a cemented Exeter ${ }^{\mathrm{TM}}$ stem was inserted. For the eight revised hips the mean postoperative HHS was 88 (range, 41-100) and the mean postoperative OHQS of 20 (range, 12-54) at a minimum followup of 1 year (average, 4.5 years; range, 1-10 years).

\section{Discussion}

Degenerative cartilage disease of the hip in very young patients is often secondary to an underlying disease. Several options are available to deal with acetabular defects in young patients. The most used is an uncemented cup and if necessary a reinforcement ring, placed with or without bone grafts. Since 1979 we have preferred to reconstruct very young patients with a cemented THA, and in case of bone deficiencies, bone impaction grafting in combination with a cemented prosthesis. The purpose of our study was to (1) determine survival of the prosthesis in patients younger than 30 years and whether differences exist between hips placed with and without acetabular bone impaction grafting; (2) determine the clinical outcome of the surviving hips; (3) define radiological failures; and (4) determine complications and current state of revisions.

We draw the reader's attention to several limitations. First is the use of multiple implant designs; however, all types were cemented. As a referral center, we have not referred cases to other hospitals and therefore we have included all diagnoses and acetabular bone defects during the time of the study except those who had an implant based for tumors. Apart from the different implants there was no selection bias since we used the same treatment protocol in all patients, and in case of bone stock deficiencies, we reconstructed the defect with bone impaction grafting. Further, no patients lost to followup, and we therefore believe our data are reliable [22]. Second, our study had a relatively large group (26\%) of patients with juvenile rheumatoid arthritis. These patients are probably less active compared to the other patients with a localized osteoarthritis of the hip in our series [3, 28]. In the literature, not all studies have the same conclusion relative to the outcome of THAs in rheumatoid arthritis, and in some studies, the outcome of this subgroup has reportedly worse outcomes relative to other plain osteoarthritic cases [4, 27]. Third, criteria for graft incorporation are difficult to define but Conn et al. [5] stated that graft incorporation was defined as the manifestation of a regular radiodensity and trabecular bone structure throughout the graft and host bone with a continuous trabecular pattern. In the present series, acetabular bone grafting had been performed in 29 out of 69 cases and incorporation of the grafts was seen in all cases on a consensus base by three of the authors. The criteria used are still in debate in our department and future research has to bring more detailed criteria.

Our standardized treatment protocol was associated with a 10-year survival rate of 90\% (95\% CI, 77\%-96\%). Especially in young patients, we need techniques and implants with a proven long-term survival [20], and apart from a series of patients with exclusively juvenile chronic arthritis [4, 16, 17, 19, 23], there is limited literature regarding the survivorship and complications of THA surgery in patients younger than 30 years $[2,3,9,12,20$, 28-30] (Table 4). For the acetabular side, Torchia et al. [30] reported a revision rate for the cemented acetabular component of $43 \%$ at an average followup of 12.6 years. Sochart and Porter [29] reported an acetabular rate of revision for cemented cups of $30 \%$ at a mean followup of 20 years. Maric and Haynes [19] described a group of 17 hips, including four uncemented hips, and reported that $6 \%$ of the acetabular components were revised after an average followup of 9.3 years. We found a rate of revision of $11.6 \%$ for the acetabular component at a mean followup of 8.4 years.

We believe our protocol with bone impaction grafting is a biologically attractive approach, resulting in restoration of bone stock in these young patients. This can be a great advantage for future revisions, as can be expected in these young patients. We included in our data that from all patients who underwent revision and found reasonable functional scores except in one case. This study reflects our large experience with this technique [26] over a period of 16 years. Of the 130 total hip arthroplasties we perform every year, we have annually treated fewer than five patients younger than 30 years and only after intensive discussion and patient consent. Keeping in mind the high failure rates associated with increased demands within this cohort [2-4, 9, 12, 19, 29, 30] we think a cautious approach of these young patients is important.

Our results of cemented THA in patients younger than 30 years show a 10-year survival rate of $90 \%$ with end point revision for aseptic loosening. Loosening was mainly 
Table 4. Literature ${ }^{\#}$ of THA in patients 30 years or younger at the time of operation

\begin{tabular}{|c|c|c|c|c|c|}
\hline Study & No. hips & No. patients & $\begin{array}{l}\text { Mean age } \\
\text { in years (range) }\end{array}$ & $\begin{array}{l}\text { Mean followup } \\
\text { in years (range) }\end{array}$ & $\begin{array}{l}\text { Survivorship/revised hips } \\
\text { for all reasons (\% of total) }\end{array}$ \\
\hline \multicolumn{6}{|l|}{ Cemented } \\
\hline Cage et al. [2] & 22 & $17^{*}$ & $18.4(15-21)$ & $10.6(8-15)$ & $1(4.5 \%)$ \\
\hline Chandler et al. [3] & 33 & 29 & $28(19-35)$ & $5.6(4.8-7)$ & $7(21 \%)$ \\
\hline Chmell et al. [4] & 66 & 39 & $19.9(11-29)$ & $15.1(11-22)$ & $\begin{array}{l}70 \% \text { at } 15 \text { yrs } \\
\text { (acetabular revision) }\end{array}$ \\
\hline Halley and Charnley [12] & 68 & 39 & 25.9 & $3.3(0.5-8)$ & $\mathrm{NR}^{* *}$ \\
\hline Sochart and Porter [29] & 83 & 55 & $24.9(17-29)$ & $20(5-30)$ & $89 \%$ at $10 \mathrm{yrs} ; 65 \%$ at $25 \mathrm{yrs}$ \\
\hline Torchia et al. [30] & 63 & 50 & $17(11-19)$ & $12.6(1.6-18.6)$ & $73 \%$ at $10 \mathrm{yrs} ; 55 \%$ at $15 \mathrm{yrs}$ \\
\hline Witt et al. [32] & 96 & 54 & $16.7(11-27)$ & $11.5(5-18)$ & $24(25 \%)$ \\
\hline Busch et al. [current study] & 69 & 48 & $24.6(16-29)$ & $8.4(2-18)$ & $83 \%$ at $10 \mathrm{yrs}$ \\
\hline \multicolumn{6}{|l|}{ Uncemented } \\
\hline Kumar and Swann [17] & 25 & 16 & $24.9(15-39)$ & $4.5(1-19)$ & $3(12 \%)$ \\
\hline Odent et al. [23] & 62 & 34 & $18.3(12-31)$ & $6(3-13)$ & $90.1 \%$ at $13 \mathrm{yrs}$ \\
\hline Wangen et al. [31] & 49 & 44 & $25(15-30)$ & $13(10-16)$ & $24(49.0 \%)$ \\
\hline McCullough et al. [21] & 42 & 25 & $21(11-35)$ & $11.2(8-13)$ & $71 \%$ at $13 \mathrm{yrs}$ \\
\hline \multicolumn{6}{|l|}{ Combined techniques } \\
\hline Kitsoulis et al. [16] & 20 & 10 & $15.8(13-24)$ & $9.2(2-20)$ & $2(10 \%)$ \\
\hline Maric and Haynes [19] & 17 & 17 & $18(14-20)$ & $9.3(4.5-17)$ & $2(12 \%)$ \\
\hline Dudkiewicz et al. [9] & 69 & 56 & $23.2(14-29)$ & $7.4(2-23)$ & $14(20 \%)$ \\
\hline
\end{tabular}

\# Literature reported until July 2009.

* mixed group of patients with total hip and total knee prosthesis.

** not reported.

seen on the acetabular side and in case of an acetabular defect we recommend biological reconstruction using bone impaction grafting.

Acknowledgments We thank Jan Hendriks for his statistical support.

Open Access This article is distributed under the terms of the Creative Commons Attribution Noncommercial License which permits any noncommercial use, distribution, and reproduction in any medium, provided the original author(s) and source are credited.

\section{References}

1. Brooker AF, Bowerman JW, Robinson RA, Riley LH Jr. Ectopic ossification following total hip replacement: incidence and a method of classification. J Bone Joint Surg Am. 1973;55:1629_ 1632.

2. Cage DJ, Granberry WM, Tullos HS. Long-term results of total arthroplasty in adolescents with debilitating polyarthropathy. Clin Orthop Relat Res. 1992;283:156-162.

3. Chandler HP, Reineck FT, Wixson RL, McCarthy JC. Total hip replacement in patients younger than thirty years old: a five-year follow-up study. J Bone Joint Surg Am. 1981;63:14261434.
4. Chmell MJ, Scott RD, Thomas WH, Sledge CB. Total hip arthroplasty with cement for juvenile rheumatoid arthritis: results at a minimum of ten years in patients less than thirty years old. J Bone Joint Surg Am. 1997;79:44-52.

5. Conn RA, Peterson LFA, Stuaffer RN, Ilstrup D. Management of acetabular deficiency; long-term results of bone-grafting the acetabulum in total hip arthroplasty. Orthop Trans. 1985;9:451452.

6. D'Antonio JA, Capello WN, Borden LS, Bargar WL, Bierbaum BF, Boettcher WG, Steinberg ME, Stulberg SD, Wedge JH. Classification and management of acetabular abnormalities in total hip arthroplasty. Clin Orthop Relat Res. 1989;243:126-137.

7. Dawson J, Fitzpatrick R, Carr A, Murray D. Questionnaire on the perceptions of patients about total hip replacement. J Bone Joint Surg Br. 1996;78:185-190.

8. DeLee JG, Charnley J. Radiological demarcation of cemented sockets in total hip replacement. Clin Orthop Relat Res. 1976; 121:20-32.

9. Dudkiewicz I, Salai M, Israeli A, Amit Y, Chechick A. Total hip arthroplasty in patients younger than 30 years of age. Isr Med Assoc J. 2003;5:709-712.

10. Ethgen O, Bruyere O, Richy F, Dardennes C, Reginster JY. Health-related quality of life in total hip and total knee arthroplasty: a qualitative and systematic review of the literature. J Bone Joint Surg Am. 2004;86:963-974.

11. Gruen TA, McNeice GM, Amstutz HC. "Modes of failure" of cemented stem-type femoral components: a radiographic analysis of loosening. Clin Orthop Relat Res. 1979;141:17-27. 
12. Halley DK, Charnley J. Results of low friction arthroplasty in patients thirty years of age or younger. Clin Orthop Relat Res. 1975;112:180-191.

13. Harris WH. Traumatic arthritis of the hip after dislocation and acetabular fractures: treatment by mold arthroplasty. An endresult study using a new method of result evaluation. J Bone Joint Surg Am. 1969;51:737-755.

14. Harris WH, McCarthy Jr JC, O'Neill DA. Femoral component loosening using contemporary techniques of femoral cement fixation. J Bone Joint Surg Am. 1982;64:1063-1067.

15. Kaplan EL, Meier P. Nonparametric estimation from incomplete observations. J Am Stat Assoc. 1958;53:457-481.

16. Kitsoulis PB, Stafilas KS, Siamopoulou A, Soucacos PN, Xenakis TA. Total hip arthroplasty in children with juvenile chronic arthritis: long-term results. J Pediatr Orthop. 2006;26:8-12.

17. Kumar MN, Swann M. Uncemented total hip arthroplasty in young patients with juvenile chronic arthritis. Ann R Coll Surg Engl. 1998;80:203-209.

18. Loudon JR, Older MW. Subsidence of the femoral component related to long-term outcome of hip replacement. J Bone Joint Surg Br. 1989;71:624-628.

19. Maric Z, Haynes RJ. Total hip arthroplasty in juvenile rheumatoid arthritis. Clin Orthop Relat Res. 1993;290:197-199.

20. McAuley JP, Szuszczewicz ES, Young A, Engh CA Sr. Total hip arthroplasty in patients 50 years and younger. Clin Orthop Relat Res. 2004;418:119-125.

21. McCullough CJ, Remedios D, Tytherleigh-Strong G, Hua J, Walker PS. The use of hydroxyapatite-coated CAD-CAM femoral components in adolescents and young adults with inflammatory polyarthropathy: ten-year results. J Bone Joint Surg Br. 2006;88:860-864.

22. Murray DW, Britton AR, Bulstrode CJ. Loss to follow-up matters. J Bone Joint Surg Br. 1997;79:254-257.
23. Odent T, Journeau P, Prieur AM, Touzet P, Pouliquen JC, Glorion C. Cementless hip arthroplasty in juvenile idiopathic arthritis. J Pediatr Orthop. 2005;25:465-470.

24. Räsänen P, Paavolainen P, Sintonen H, Koivisto AM, Blom M, Ryynänen OP, Roine RP. Effectiveness of hip or knee replacement surgery in terms of quality-adjusted life years and costs. Acta Orthop. 2007;78:108-115.

25. Schreurs BW, Busch VJ, Welten ML, Verdonschot N, Slooff TJ, Gardeniers JW. Acetabular reconstruction with impaction bonegrafting and a cemented cup in patients younger than fifty years old. J Bone Joint Surg Am. 2004;86:2385-2392.

26. Schreurs BW, Slooff TJ, Gardeniers JW, Buma P. Acetabular reconstruction with bone impaction grafting and a cemented cup: 20 years' experience. Clin Orthop Relat Res. 2001;393:202-215.

27. Sechriest VF 2nd, Kyle RF, Marek DJ, Spates JD, Saleh KJ, Kuskowski M. Activity level in young patients with primary total hip arthroplasty: a 5-year minimum follow-up. J Arthroplasty. 2007;22:39-47.

28. Severt R, Wood R, Cracchiolo A III, Amstutz HC. Long-term follow-up of cemented total hip arthroplasty in rheumatoid arthritis. Clin Orthop Relat Res. 1991;265:137-145.

29. Sochart DH, Porter ML. Long-term results of cemented Charnley low-friction arthroplasty in patients aged less than 30 years. J Arthroplasty. 1998;13:123-131.

30. Torchia ME, Klassen RA, Bianco AJ. Total hip arthroplasty with cement in patients less than twenty years old: long-term results. J Bone Joint Surg Am. 1996;78:995-1003.

31. Wangen $\mathrm{H}$, Lereim $\mathrm{P}$, Holm I, Gunderson R, Reikerås O. Hip arthroplasty in patients younger than 30 years: excellent ten to 16-year follow-up results with a HA-coated stem. Int Orthop. 2008;32:203-208.

32. Witt JD, Swann M, Ansell BM. Total hip replacement for juvenile chronic arthritis. J Bone Joint Surg Br. 1991;73:770-773. 